\section{An E-Government Initiative to Support Supply Chain Integration for Small to Medium Sized Enterprises: Successes and Challenges}

\author{
Hsin Chen* \\ Department of Business System \\ Business School \\ Bedfordshire University, UK \\ Anastasia Papazafeiropoulou \\ School of Information Systems \\ Computing \& Mathematics \\ Brunel University, UK \\ Chingfang Wu \\ Department of Business Administration \\ Yu Da Univeristy, Taipei, Taiwan \\ ${ }^{*}$ corresponding author
}

\begin{abstract}
The paper highlights the importance of the e-government initiative to support the supply chain integration among Small and Medium Size Enterprises (SMEs). It has been reported that organisations need to integrate their Information Technology (IT) infrastructures to support the integration of their supply chains to increase their efficiency. However, the current research suggests that Small and Medium Size Enterprises (SMEs), due to their lack of expertise and financial resources to invest in the necessary technologies, seem to need further support from the government in their efforts to adopt IT. Therefore, the role of the government is fundamental in supporting them to adopt supply chain management technologies,
\end{abstract}

especially in geographical contexts such as this of Taiwan. A case study is therefore carried out in this paper to study an initiative taken in Taiwan by the government in order to help the supply chain integration of Taiwanese IT manufacturing companies. The findings suggest that the adoption of IT by SMEs (i.e. suppliers) is very much dependent on external forces (resource-dependency view), thus the government has a very important role to play when it comes to supporting SMEs to join supply chain networks. In doing so, this research provides a broader understanding of the phenomenon of e-government initiatives to support supply chain integration in practice.

Keywords: E-government Policies, Integration Technologies, Supply Chain Management, Information Technology, SMEs, Case Studies.

\section{Introduction}

The use of Internet-based Computing and Communications (ICT) has emerged as a key enabler to help organisations achieving greater coordination and collaboration among supply chain partners and automate the supply chain process. This has created competitive pressures as manufacturers and distributors are forced to become more responsive to the retailers and consumers. These pressures are forcing manufacturers/buying organisations to reduce costs, decrease order cycle times, and improve their operating efficiencies. As a result, manufacturers are under pressure to better manage the supply chain and to improve manufacturing efficiency and logistics operations while remaining responsive to changing market conditions and customer demands. The increasingly complex global relationships among suppliers, manufacturers, distributors, retailers and consumers compound these pressures (Kalakota and Robinson, 2001). Nowadays, the use of technologies help organisations to better manage their supply chains, as supply chain management applications built on technology platforms have enhanced the ability of organisations to integrate their processes through collaborative information sharing and planning (Charles et al., 2001; Kalakota and Robinson, 2001). For example, integration technologies like Enterprise Application Integration (EAI) and Web Service are being used to support the integration of supply chains. With supply chain integration, companies are able to anticipate customers' desires and meet their demands. A competitive 
firm has to have the ability to acquire the goods and services it needs just when and where it needs them, at a favourable price, and with acceptable payment and delivery terms. A competitive firm needs to directly manage the flow of goods through its distribution networks in a cost-effective manner. Organisations have come to realise that they can achieve this by integrating their supply chains. Implementing supply chain integration can save costs for the company in many ways. It can lower the costs of labour, increase flexibility, achieve faster response times and cut down on the occurrence of errors on paper-based operation, reduce unauthorised buying outside preferred supplier agreements, and reduce stocking, hence achieving competitive advantage (Essig and Arnold, 2001; Lee and Whang, 2001). Automation process can also shorten the cycle time from ordering to distribution, thus resulting in enhanced production ability and increased efficiency. As for suppliers, they can also benefit from supply chain integration as this will shorten the business transaction cycle, lower capital costs in stocking, lower labour costs, increase efficiency, enhance accuracy, reduce handling times and increase delivery speed (Chen et al., 2003).

Although many efforts have been made by companies to use integration technologies to support their supply chain integration strategy, adoption problems still exist. This is due to the fact that most of their suppliers are SMEs and their ability and resources are limited; therefore, integrating their systems with their buying organisations seems to be a significant problem for them. The supply chain cannot be efficiently integrated without support and cooperation from the external forces such as manufacturers, suppliers or the government (Pan et al., 2006). According to Navarro et al. (2007), the government plays a crucial role in supporting SMEs' IT adoption. Groznik et al. (2008) claim that e-government supply chain implementation is only feasible if it is introduced hand in hand with the government and private companies. The success of an e-procurement system requires the analysis and design of new and efficient internal and supplier-connected processes in order to minimise the meaningless circulation of information (Panayiotou et al., 2004; Groznik and Trkman, 2009). According to the literature, government promotion mechanisms can be a major enabler for IT adoption (Gibbs et al., 2003). Shore (2001) suggests that the support the government can offer can take the form of openness in the use of standards and cross-border data low (Shore, 2001). Groznik and Trkman (2009) and Lee et al. (2005) report that the introduction of e-procurement brings several challenges that are mainly addressed by the Supply Chain Management (SCM) concept in private companies. Despite certain calls to also study SCM in the e-government context, this seems to remain an under-researched area.

In line with that the research question of this study is 'Are SMEs' integration technologies adoption decisions highly dependent on external forces such as the government?" and we study this in the geographical context of Taiwan. This study therefore examines a government initiative project (the case of Industry Automation Programme) that took place in Taiwan as a way to support SCM integration among SMEs in the IT manufacturing sector. The Industry Automation Programme is one of the pivotal e-government initiatives introduced by the Taiwanese government to facilitate Business-to-Business (B2B) e-commerce operation capability in the IT industry to enhance Taiwan IT industry's core competence, and to push forward 2500 SMEs in the IT industry, to establish operation capability and to promote e-commerce and supply chain integration adoption activities.

The remaining paper is structured as follows. In the next section, we provide a review of our theoretical basis to examine the adoption of integration technologies and the role of the government. We then proceed to present and discuss the research methodology that guided this research. This leads us to the fourth section of our paper, in which we present the details of the government initiatives, followed by section 5 were we describe the findings obtained from the case studies. The sixth section of the paper presents the discussion of our reported findings in relation to our theoretical basis. Finally, we conclude by providing the limitations of the study and the future direction of the research on this topic.

\section{Literature Review}

\section{Integration Technologies Adoption by SMEs and the Role of the Government}

Due to SMEs' inadequate resources, limited knowledge, lack of 'know-how' about IS, and several other constraints, some researchers have found that small businesses generally face greater risks in IS implementation and the use of IT than 
large businesses (Cragg and King, 1993; Cragg and Zinatelli, 1995; lacovou et al., 1995). Thus, managers in SMEs have been characterised as having reservations about the adoption and use of IS (Chang and Powell, 1998; Thong, 2001). As a result, these reservations have impeded the full exploitation of the benefits and successes that such organisations can achieve from IS. In the early days, SMEs tended to use IS as tools to automate their standard administrative functions such as accounting, budgeting and inventory control. Until recently, there has been growing literature addressing the issues of using IS for a competitive advantage amongst SMEs (Pollard and Hayne, 1998). According to Lin et al. (1993), the increasing interest in the strategic use of IS by SMEs is based on three factors: (1) the increased adoption of IS and its effective use by competitors, (2) a decrease in the cost of IS so that it is accessible to SMEs, and (3) the ability for IS to allow SMEs to mask their size from their external partners. For these reasons, the researcher suggests that some SMEs have turned to the adoption of integration technologies as a new strategy to improve their competitiveness (Chen et al., 2003).

The review of the literature has shown that only a few prior studies have focused on integration technologies in small businesses, as reported by Daniel (2003), Hughes et al. (2003), lacovou et al. (1995), Kuan and Chau (2001), Ravarini et al. (2000), Tagliavini et al. (2002), and Waarts et al. (2002). Among these studies on adoption, the model proposed by lacovou et al. (1995) presents the most comprehensive research that focuses on the adoption of EDI in small businesses (Kuan and Chau, 2001). However, most of the literature on this subject that has been reviewed mainly focuses on the adoption of EDI and ERP, with studies related to EAI and Web Services adoption in SMEs proving to be largely lacking. This might be due to the fact that EAI and Web Services are only beginning to emerge and are in the early stages of adoption (Hailstone and Perry, 2002). Another reason might be that SMEs feel it unnecessary to adopt EAI or Web Services due to the extra costs and expertise required to implement these integrative technologies. The studies mentioned above are mainly focused on internal factors related to SMEs' decision to adopt technologies with less focus on the external influences.

In our study we move our focus from the internal factors affecting IS adoption as presented in the table above and we see how SMEs respond to external influences such as those of the government. IT adoption in Taiwan and supply chain technology adoption in particular have been studied in the past with a number of factors identified as relevant to companies' decision to invest in these technologies. These factors are organisational, extra-organisational, governmental, industrial and cultural (Thatcher, et al., 2006). Within these factors the role of the government in creating a fertile environment for the companies to invest in and reap the benefits of IT has been widely emphasised (Oxley and Yeung, 2001). More specifically, among other factors relating to e-commerce adoption in the USA, such as pressure from trading partners, the government pressure emerges as the strongest driver, especially for companies trading with the government (Hsu, at el., 2006). The support the government can offer can take the form of data infrastructure and security, openness in the use of standards and cross-border data flow as well as creating an adequate educational system which is able to produce a highly skilled workforce (Shore, 2001). When it comes to SMEs and e-commerce in particular it has been reported that government promotion mechanisms such as telecommunications liberation and increasing pressure on firms can be a major enabler for adoption (Gibbs et al., 2003). The famous successful example of EDI adoption in Singapore shows the power that the government has in persuading companies, especially through educational programmes made to promote IT adoption (Soh, et al., 1993). Korea was also an interesting example of successful government intervention for broadband adoption (Choudrie, et al., 2003). Lee and Kim (2007) report that government initiatives on the IS/IT project have supported companies, and this involved facing a challenge and speeding up their reengineering process. Therefore, the government provides a trigger to help SMEs actually catch up with the advances of technologies. In the case of Taiwan, the building of the national ICT infrastructure and regulatory reform over many years were policy choices that helped the advancement in the adoption and use of technologies such as supply chain integration (Wang, 1999). Nevertheless, the application of e-government initiatives especially in countries on the development curve is not always straightforward and there are a number of risks coming into play such as resistance to change and lack of engagement from the public (Ciborra and Navarra, 2005). Similar to companies, governments might be under pressure from other governments or international organisations to 
perform in a certain way and follow policies that are not well thought of (Yildiz, 2007). These challenges in the implementation of e-government initiatives have been formally categorised as: (1) information and data, (2) information technology, (3) organisational and managerial, (4) legal and regulatory, and (5) institutional and environmental (Gil-Garcia and Pardo, 2005).

In this paper we are examining a government initiative that took place in Taiwan as a way to support supply chain integration among SMEs in the IT manufacturing sector. By taking a resource-dependency view we examine how external pressures such as those coming from the government affected the adoption of IT and active participation to the project.

\section{Resource-dependency View}

According to the literature, small businesses are under increasing pressure to employ IS to maintain their competitive positions. At the same time, there are more barriers to IS implementation in small businesses than there are for large businesses, due to the high capital investment and skilled manpower involved in implementing and operating IS (Thong, 2001). Welsh and White (1981) pointed out that resource constraints (time, finance and expertise) in small businesses are based on the concept of resource-based theory. Welsh and White (1981) state that: (1) SMEs have to control their cash flows carefully, as they do not have unlimited funds for their IS project; (2) SMEs tend to choose the cheapest system, which may be inadequate for their purposes; (3) SMEs usually underestimate the amount of time and effort required for adopting integration technologies; and (4) SMEs normally engage consultants and IT vendors to develop and support their IS (Thong, 2001). Levy et al. (2001) report that large firms use IS/IT to add value rather than simply to reduce costs. SMEs' exploitation of IS tends to mimic the early use in large firms - cost reduction. However, SMEs may use IS to co-ordinate internal activities, to add value through collaboration, particularly with customers, and occasionally to innovate (Levy et al. 2001). For example, SMEs might prefer to outsource most of their activities, whereas large companies might prefer to outsource only those activities which are not directly related to their business strategies, or even to manage these activities totally on their own. Resources such as time, finance, and expertise, all necessary for planning, represent the most critical difficulties for small businesses (Cohn and Lindberg, 1972). Thong (2001) reports that small businesses tend to have insufficient knowledge to implement IS successfully, thus, SMEs might need to seek external expertise (e.g. IT vendors, etc.).

Attewell (1992) claims that the role of external entities (e.g. consultants and IT vendors) is to act as knowledge providers in lowering the knowledge barrier or knowledge deficiency on the part of potential IS adopters. Small businesses tend to delay in-house is implementation as they have insufficient knowledge to implement IS successfully (Thong, 2001). Shin (2006) added that the utilisation and application of IT among SMEs have been slow due to their weak infrastructure for IT diffusion, which includes diverse standardisation, weak logistic support, legal structure, low transparency in accounting systems, and unrecorded transactions. For these reasons, some researchers have found that small businesses generally face greater risks in IS implementation and the use of IT than large businesses (Cragg and King, 1993; Cragg and Zinatelli, 1995; lacovou et al., 1995). Thus, managers in SMEs have been characterised as having reservations about the adoption and use of IS (Chang and Powell, 1998; Thong, 2001). However, these reservations have not always obviated the benefits and successes that such organisations can achieve from IS. In the early days, SMEs tended to use IS as tools to automate their standard administrative functions, e.g. accounting, budgeting and inventory control, etc. There has been a growing literature addressing the issues of using IS for a competitive advantage amongst SMEs (Pollard and Hayne, 1998). According to Lin et al. (1993), the increasing interest in the strategic use of IS by SMEs is based on three factors: (1) the increased adoption of IS and its effective use by competitors, (2) a decrease in the cost of IS so that it is accessible to SMEs, and (3) the ability for IS to allow SMEs to mask their size from their external partners. Hughes et al. (2003) also claim that under the right conditions, SMEs could be successful innovators of new technology. These conditions include: (1) low costs, (2) relevance of and flexibility to business needs, and (3) previous experience with technology, while high costs, lack of relevance and flexibility and lack of previous experience with technology are proven factors that restrict the adoption of traditional inter-organisational systems amongst SMEs.

For these reasons, resource-dependency theory is used here to explain this situation. 
Resource-dependency theory is a theory of organisation that seeks to explain organisational and inter-organisational behaviour in terms of those critical resources that an organisation must have in order to survive and function (Johnson, 1998). Thompson (1967) represents one of the earliest attempts to examine the flow of externally-based resources into organisations and the implications of the uncertainty surrounding this flow for organisational-level action and behaviour. Thompson notes that an organisation's need for resources, and the subsequent dependence resulting from this need, create problems for organisational managers. Given that no one organisation is self sufficient, organisations are forced to enter into exchange relations with the other actors, entities, and organisations in their environments. The unequal distribution of needed resources results in inter-dependent organisational relationships. For any given organisation, the need for resource acquisition creates dependencies between the organisation and other organisations in its environment. Johnson (1998) suggests that organisational leaders seek ways to mitigate the disruptive effects of external dependence. Such attempts underscore the implicit view of organisations as entities driven by the need to adapt. Based on this, he proposes the logic of resource-dependency theory from the perspective of the focal organisation framework. This framework explains the general logic and flow associated with resource-dependency theory from the perspective of the focal organisation, i.e. a given organisation of interest. The context of the focal organisation is the larger environment in which it exists. For the organisation, the environment represents many things: resources; other organisations; organisational sets and networks; existing and emergent inter-organisational exchange relationships; dependence; uncertainty, etc.

Based on the literature review in this section, the following Research Issue (RI) arises for further investigation:

\section{RI: Are SMEs' integration technologies adoption decisions highly dependent on external forces such as the government?}

\section{Research Methodology}

The Industry Automation Programme initiated by the Ministry of Economic Affairs, Technology Department, of the Taiwanese government is the government initiative used in this paper. The goals of the programme were to facilitate Business-to-Business (B2B) e-commerce cooperation between IT manufacturers. Apart from interviews with the government agents involved in the project, multiple case studies were conducted to investigate the supply chain integration approach followed by the Taiwanese IT manufacturing industry. Fifteen enterprises in the IT manufacturing industries were selected for in-depth case study research in order to extract their opinions on the usefulness of the project and their views on the support they got from the government. Case study research is employed due to the fact that this research method generally answers one or more questions, which begin with "how" or "why". The questions are targeted to a limited number of events or conditions and their inter-relationships (Yin, 1989). The case study approach has been successfully employed for in-depth investigation of a variety of IS issues including adoption of IS/IT (Mustonen-Ollila \& Lyytinen, 2003; Caldeira \& Ward, 2002), IS \& organisation change (Avgerou, 2001), IS development (Gallivan \& Keil, 2003), IS implementation (Amrani et al., 2006) and IS evaluation (Irani et al., 2005). The successful use of case study to examine a number of IS issues provided further support to employ case study for conducting this research. Since not much is known about adoption of integration technologies by SMEs for supporting supply chain integration, the case study approach was considered applicable to undertake this study. One of the most important sources of case study information is the interview (Yin, 1994). Interviews are considered to be the main tool of the qualitative researcher for data collection (Denzin and Lincoln, 1998), and one of the frequently used data collection tools (Amrani et al., 2006; Avgerou, 2001; Caldeira \& Ward, 2002; Currie \& Willcocks, 1998; Gallivan \& Keil, 2003; Irani et al., 2005; Mustonen-Ollila \& Lyytinen, 2003) also used for this research. Indeed, interviews are the primary data source for interpretive case studies. According to Walsham (1995b), interview is the method by which the researcher can best access the interpretations that participants have regarding the actions and events under investigation. An added benefit is that it allows the authors to step back and examine the interpretations of fellow participants in some detail. This is an advantage that other methods may not allow. There are various forms and types of interviews. According to Denzin and Lincoln (1998), there are three major types: (1) structured, (2) semi-structured, and (3) unstructured. 
In the context of this research, interviews constituted the main data source in the cases. The very important source of evidence of this study has been the mixture of structured, unstructured and semi-structured in-depth interviews with the parties involved in the activities under investigation. Structured interviews entail more structured questions, along the lines of a formal survey. In this research, the structured interviews were based on the interview agenda. By the interview agenda, the interviewees replied to specific questions regarding supply chain integration. The interview agenda focuses on collecting data from the following areas: (1) general background, (2) business information of manufacturers, and (3) business information of small suppliers. Semi-structured interviews took place using a semi-structured interview agenda. The interviews lasted between 60 and 90 minutes, were tape recorded and subsequently transcribed. Unstructured interviews were also used, which dealt with discussions that the authors had with interviewees, but without using a structured or semi-structured type of interview. In the majority of cases, structured or semi-structured interviews took place in the interviewee's office. Using unstructured interviews, some important data regarding the case studies were collected (e.g. inside information regarding resistance to change, politics issues, business complexity, etc.). The interview guide included a total of 40 open-ended questions designed to explore the general information of the firms (10 questions), the business information about the manufacturers and suppliers involved in the project (13 questions), questions related to politics issues and business complexity (7 questions), and questions about the Industry Automation Programme with the government agents (10 questions). Note that where the physical presence of the authors was not possible, telephone interviews with the organisers were conducted, and completed questionnaires from the participants were sent later to the authors by e-mail and surface post. Additionally, The Industry Automation Programme case study was conducted over a period of two and a half years to observe the case in different stages so as to give rich empirical evidence for an interpretive analysis of the integration technologies' adoption process. The authors first interviewed the members of the case companies in 2001, using structured and semi-structured interviews (the project had just begun). After that, the interviews took place again with the same case companies in 2002, using semi-structured interviews. In 2004, the authors revisited some of the case companies again (the project is now complete and mature). The adoption activities that took place in a different period of time, but were organised by the same parties, gave the authors the possibility to discuss the same issues with the same people in a different time context. Consequently, the results of the study go well beyond a snapshot of a specific activity in a given time frame, but take into consideration events that took place over a long period of time, as well as views about the past and future of the activities under investigation. The government agents were contacted throughout the three research cycles in order to keep them involved and to make sure we cross check views taken by the case study companies (see Figure 1).

\section{Figure 1: Case-Based Artefact Research}

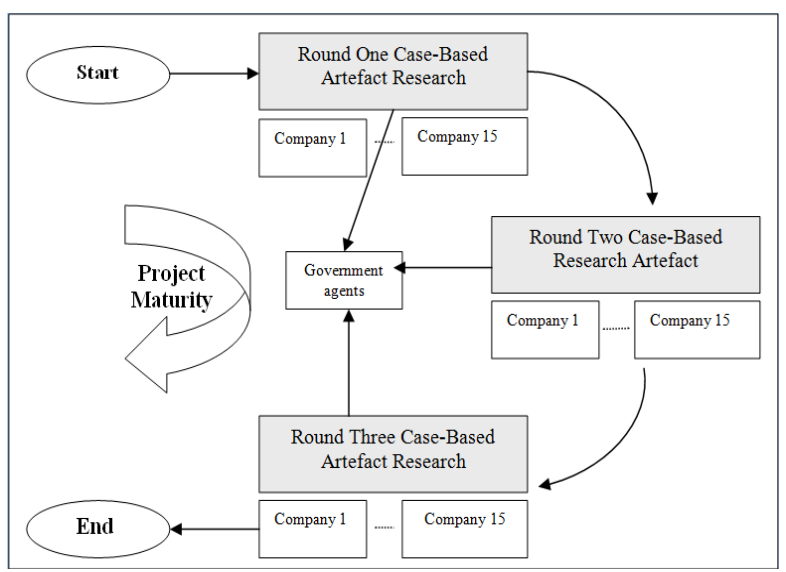

In all the case studies, the interviewees selected for structured interviews were mainly: the project manager, MIS department manager, a consultant (internal or external), and, in the case of the government, relevant agents, all of whom have been directly involved in the Industry Automation Project as organisers and are supported by the government. Such stakeholders had an important role during the decision-making process for integration technologies adoption and Industry Automation Plan, as well as during the implementation. Therefore, it was considered important to select a cross-section of roles in the Industry Automation project to obtain the views of stakeholders at different levels in the organisations. This provides a better understanding of the phenomenon of integration technologies adoption.

Apart from the companies involved in the Industry Automation Programme, the authors collected a number of data related to the government side of the initiate throughout the duration of the project (1999-2005) from interviews with government 
agents involved in the project (5 telephone interviews lasting for half an hour each), as well as official reports. Secondary sources such as official government reports were used to find out the results and the variable aspects of the Industry Automation Programme. The advantage of using the secondary resources in this research is that the authors were following the project from the start (since 1999) and thus have a better understanding of the consequent and the final official reports. Therefore, the authors had the opportunity to see inside and to understand immediately what the participants (both government agencies and companies) were claiming by tailoring subsequent questions based on the information that the participant had provided from the interview, as well as information coming from the official reports (Mack et al, 2005).

The data were analysed using thematic analysis (Boyatzis, 1998). Thematic analysis is rarely acknowledged but widely used in the analysis of qualitative data and has been presented as an accessible and flexible approach to search for meanings in informants' talk (Braun and Clarke, 2006). There are two primary ways where themes or patterns can be identified in thematic analysis: inductive (Patton, 1990) or deductive (Hayes, 1997; Boyatzis, 1998). An inductive approach means that the themes identified are strongly linked to the data themselves, which leads this form of thematic analysis to bear similarities to grounded theory. The deductive or 'theoretical' thematic analysis is driven by the researcher's theoretical approach. In this type of thematic analysis, there is less rich description of the data and more detailed analysis of some aspects of the data. In our study we used the theoretical lens of resource-dependency theory but also kept an open but focused approach to the government role in the diffusion of supply chain integration to SMEs. These approaches were based on the literature themes analysed in sections 2.1 and 2.2 and were used as part of the open discussion with the interviewees. Thus, using first deductive and thereafter inductive techniques, we followed the steps of thematic analysis suggested by Braun and Clarke (2006):

1. Familiarising ourselves with the data. During this phase the empirical data were read with the view to identify the current status of the Industrial Automation Programme developments and the role of the government in this initiative.
2. Generating initial codes. The data were organised into common themes that emerged from the interviews. To facilitate the analysis, a table was created and the common themes were presented on the rows while the interviewees' responses were presented on the columns (i.e. one column for each interviewee).

3. Searching for themes. As the authors performed the initial analysis, they became increasingly interested by the observation that government agents, manufacturers and suppliers repeatedly referred to the challenge of integrating the supply chain and their need for support from the government.

4. Reviewing themes. As the analysis evolved, the authors applied a 'second read' approach to the data analysis while reviewing the developed themes. During this 'second read', the empirical data were analysed by careful reading and reflection on the field notes and the transcribed interviews and through frequent discussions between the authors in order to extract the key perceptions of the Industrial Automation Programme with a focus on the government's role.

5. Defining and naming themes. The extraction of the relevant themes was made around the Industrial Automation Programme case companies and government agents. The process of organising data involved the first author identifying patterns and quotations in the raw text, excerpting them and bringing them to the other authors for joint discussion and refinement over a period of 6 months and more than 30 hours of discussion.

6. Producing the report. This was the writing exercise that led to this paper, as the themes identified in the analysis were related back to the research question and literature producing an academic paper. Having described the research approach of this study, the next section presents the analysis of the government initiative project.

\section{The government initiative: the Industry Automation Programme}

The Industry Automation Programme was executed in Taiwan by the Ministry of Economic Affairs' Technology Department, and started on $3^{\text {rd }}$ June 1999. The main goals of this programme were to establish B2B e-commerce operation capability in the IT industry to enhance Taiwan's IT industry's core competence, and to push forward 
2,500 SMEs in the IT industry, to establish operation capability; meanwhile, it also aimed to overcome any problems while promoting e-commerce in the IT industry and serve as the reference for promotion in other industries. This e-commerce grant programme of the IT industry is divided into two categories - A-Plan and B-Plan where A-Plan is for the International Procurement Office (IPO) of foreign companies, and its annual procurement amount should be over 1.5 billion USD $^{1}$. The company proposed its e-commerce plan with its supply chain companies and other famous Taiwan IT service companies. The emphasis of the programme is to enhance the B2B e-commerce operation capability between Taiwan's main IT product suppliers and international buyers. Besides, helping domestic companies to set up an international open standard and training and educating local suppliers are also important goals. Three companies, IBM, HP, and COMPAQ, have been approved for the A-Plan (Yuan, 2000). The AB project began in 1999 and was completed in 2001 (http:/itap.tdp.org.tw). Later, the government continued to integrate and support further the Industry Automation Programme and created the $C, D, E$ plan which was based on the $A B$ plan and included enhanced services such as e-cash, e-delivery and e-engineering collaboration, to help the involved companies integrate supply chain and cash flow into the Industry Automation Programme. The C, D, E plan began from 2001 and most of the C, D, E projects were completed in 2004 according to the official report which was published by the Department of Industrial Technology in 2005 (Farn, et al., 2005).

The B-Plan, which the case study is focused on, is predominantly for domestic companies of the supply chain, which is manufacturing IT products or key components and its annual revenue should be over 10 billion N.T ${ }^{2}$ Dollars. Besides, it should have over 100 suppliers of components, and forms the complete supply chain. The emphasis of the B-Plan is to help construct the B2B e-commerce operation capability between the predominant company and its own suppliers. Moreover, helping the company to set up the international open standard and integration technologies, providing an on-line training and education course for its suppliers, and encouraging IT service companies to provide the general solution and Application Service Provider (ASP) service for Taiwan SMEs

\footnotetext{
130 N.T. Dollars $=1$ U.S. Dollar

${ }^{2}$ N.T Dollars $=$ New Taiwan Dollars
}

are also important goals. The policy lays special responsibility on the predominant company for the cost of application set-up and upgrade for developing the e-commerce system between suppliers. There are 15 large Taiwanese companies that have been approved for the B-Plan (Yuan, 2000). At last, 15 companies came into existence, together with more than 1,800 suppliers to set up e-supply chains of procurement. The system connections between the case companies and their suppliers are shown in Figure 2.

\section{Figure 2: Architecture of Industry Automation Programme}

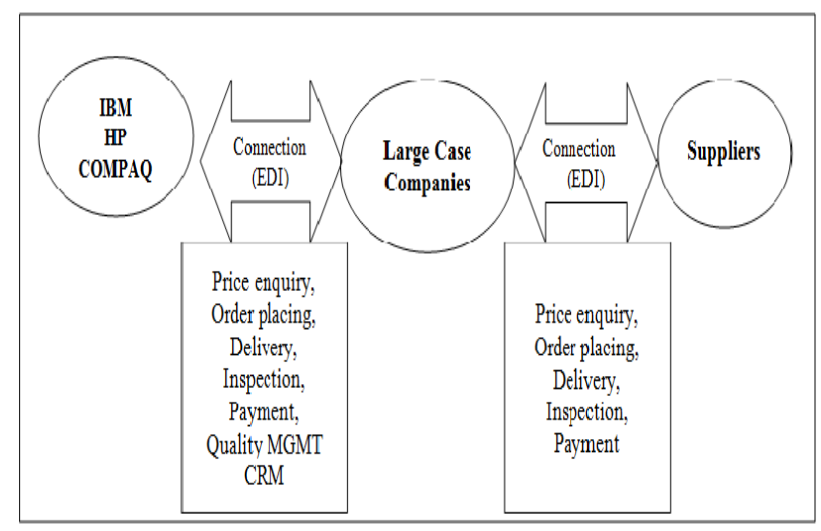

A secured end-to-end B2B collaborative commerce environment will be the base to support exchange transactions. It consists of 5 categories of construction: (1) platform; (2) network; (3) firewall; (4) data transformation standard; and (5) data warehouse. A B2B solution platform connected to the Internet and protected by proper firewalls among trading companies inside the community provides the core and safeguard to everything performed by the exchange. Data transformation standards are the common languages that all participants use to communicate, like EDI, XML, etc. EDI has been the most popular standard that many trading companies use to communicate plain text information. Data warehouses play an important role to record all activities happening in the community. The transaction recorded will provide basic information for judgement when a business argument occurs. By applying data mining technology, the information may reflect customers' characteristics and provide the base for a future Customer Relationship Management (CRM) system to improve customer satisfaction and possibly increase the business volume. Data warehouses 
can turn into a community's knowledge base by accumulating valuable information.

The interconnections between the buyers, customers and suppliers are based on EDI over Internet technology. EDI over Internet technology is used for the following reasons:

- Internet software and online marketplaces (eMarkets) have provided a platform for collaboration beyond what was achievable in the past. The Internet provides an inexpensive connection, an open and scalable architecture, and common software and communication standards to support interoperability between the islands of information residing throughout the supply chain.

- Documents (purchase orders, confirmations, shipping notices and invoices) are typically transmitted over private, secure networks known as VANs. Although EDI helps reduce transaction costs, it typically requires human intervention to process the documents, and often requires manual data re-entry. EDI does not support the purchase decision process, and the expensive VAN costs have excluded smaller companies from participating.

- EDI technology has many disadvantages, such as it does not support real-time interactions between trading partners, and requires same proprietary software on both ends, etc. These problems can be improved by adopting e-commerce-based EDI. For example, this type of EDI technology automates both sides (buyer and supplier) and it is an inexpensive Web browser user interface, etc. Table 1 summarises the disadvantages of EDI and the advantages of e-commerce-based EDI as reported by the case companies.

Table 1: EDI Disadvantages vs. EDI Over Internet Advantages

\begin{tabular}{|ll|ll|}
\hline \multicolumn{1}{|c|}{ EDI Disadvantages } & \multicolumn{1}{c|}{ e-Commerce-Based EDI Advantages } \\
\hline$\bullet$ & Not suited for many buyers and suppliers & $\bullet$ & Automates both sides - buyer and supplier \\
- & Does not support real-time interactions \\
between trading partners (i.e. order status) & $\bullet \quad$ Internet platform enables open marketplaces or \\
- $\begin{array}{l}\text { Primarily used for selected direct goods (high } \\
\text { dollar volume with few suppliers) }\end{array}$ & $\bullet \quad \begin{array}{l}\text { Automates approval process } \\
\text { Requires same proprietary software on both } \\
\text { ends }\end{array}$ & $\bullet \quad$ Eliminates paperwork \\
& $\bullet \quad$ Enforces purchasing policies \\
& $\bullet \quad$ Inexpensive Web browser user interface \\
\hline
\end{tabular}

According to the official report, there are 3 major international companies, IBM, HP and Dell, that set up their own e-procurement system and embedded it with 31 local electronic providers' systems. The government has played the role of contact window between the international major electronic and local electronic providers. Therefore, the A-plan that was initiated by the government enhanced the international competiveness of the local electronic providers. The B-plan continued to focus on the e-procurement system and to integrate the local system and component manufacturers. Therefore, there are 40,000 local electronic companies that joined the programme and set up an e-procurement system that was embedded into their supply chain system. Overall, the $A B$ project created advantages for the local electronic companies to integrate the international companies' procurement (Fan and Huang, 2005). The C, D, E plan focused on integrating the cash flow, delivery and engineering collaboration for the local electronic companies and semi-conductor manufacturers which are based on the companies projects in their e-cash flow system, 11 projects in the e-delivery system and 6 projects in the engineering collaboration. The $\mathrm{C}$ programme

received the e-Asia Award, which is rewarded to an achievement in e-business that was enhanced by a government project, in 2004 (http:// itap.tdp.org.tw).

The D plan has invested NT 1,044,143,000 dollars and it brought NT 1,034, 171,900 dollars of annual extra income, according to the Ministry of Economy report. The plan has also extended to the global business logistics integration plan and e-business plan. The advantages of the $D$ plan are that it has supported the joined companies which have created a stronger logistics network, it has enhanced the handling abilities of the information services provider, integrated the banks' services and raised the competiveness of the business. There are only 6 companies involved in the $E$ project but it brought 21 international companies to 
adopt several automation system functions, such as design activities, supporting activities and information infrastructure etc. The companies gained the results in three main dimensions: cost reduction, improved product quality and a reduction in products' time-to-market (Farn, et al., 2005). See Figure 3 for the project structure.

Figure 3: The E-Government project structure

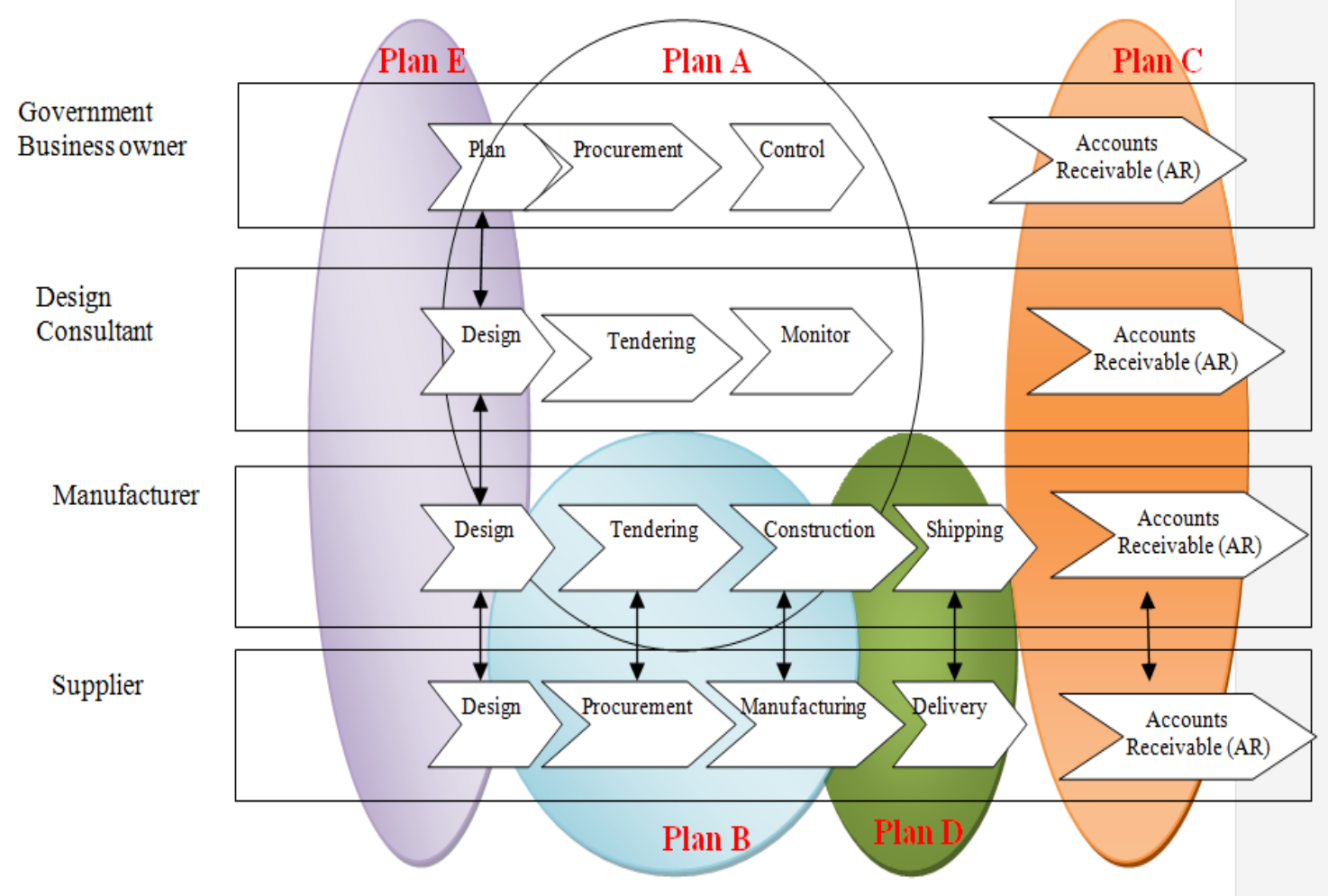

\section{Successes and Challenges}

The result of the ABCDE plan has evolved into a global logistics plan in the main project of the nation development in 2008. The government continues to act as an important mediator to support the local companies and help them to improve their global logistic abilities and enhance their integration efficiencies(Farn, et al., 2005). See Table 3 for the summary of the Industry Automation Programme results. 
Table 3: Summary of the Industry Automation Programme and Results

\begin{tabular}{|c|c|}
\hline $\begin{array}{c}\text { Industry } \\
\text { Automation Plan }\end{array}$ & Results \\
\hline A-plan & $\begin{array}{l}\text { Enhanced the international competiveness of the local electronic } \\
\text { providers }\end{array}$ \\
\hline B-plan & $\begin{array}{l}\text { Integrated the local system and component manufacturers. } 40,000 \text { local } \\
\text { electronic companies joined the programme and set up an } \\
\text { e-procurement system that was embedded into their supply chain } \\
\text { system. }\end{array}$ \\
\hline $\begin{array}{l}\text { Phase 1: } \\
\text { A-B plan began in } \\
1999 \text { and was } \\
\text { completed in } \\
2001\end{array}$ & $\begin{array}{l}\text { 1. Created the advantages for the local electronic companies to } \\
\text { integrate the international companies' procurement. } \\
\text { 2. Enhanced the B2B e-commerce operation capability between } \\
\text { Taiwan's main IT product suppliers and international buyers. } \\
\text { 3. Helped domestic companies to set up an international open } \\
\text { standard, with training and educating local suppliers also as } \\
\text { important goals. } \\
\text { 4. Constructed the B2B e-commerce operation capability between } \\
\text { the predominant company and its own suppliers. } \\
\text { 5. Set up the international open standard and integration } \\
\text { technologies, providing an on-line training and education course } \\
\text { for its suppliers. } \\
\text { 6. Encouraged IT service companies to provide a general solution } \\
\text { and Application Service Provider (ASP) service for Taiwan SMEs. }\end{array}$ \\
\hline C plan & $\begin{array}{l}\text { Received the e-Asia Award, which is rewarded to an achievement in } \\
\text { e-business that was enhanced by a government project, in } 2004 \text {. }\end{array}$ \\
\hline D plan & $\begin{array}{l}\text { 1. Invested NT 1, 044, 143,000 dollars and it brought NT 1,034, } \\
171,900 \text { dollars of annual extra income according to the Ministry of } \\
\text { Economy report. } \\
\text { 2. Supported the joined companies that have created a stronger } \\
\text { logistics network, enhanced the handling abilities of the information } \\
\text { services provider, integrated the banks' services and raised the } \\
\text { competiveness of the business. }\end{array}$ \\
\hline E plan & $\begin{array}{l}\text { Brought } 21 \text { international companies to adopt several automation } \\
\text { system functions, such as design activities, supporting activities and } \\
\text { information infrastructure etc. The companies gained the result in } \\
\text { three main dimensions: cost reduction, improved product quality } \\
\text { and a shorter time-to-market for products. }\end{array}$ \\
\hline $\begin{array}{l}\text { Phase 2: } \\
\text { C-D-E plan } \\
\text { began in } 2001 \\
\text { and was } \\
\text { completed in } \\
2004\end{array}$ & $\begin{array}{l}\text { 1. } 11 \text { projects in the e-delivery system and } 6 \text { projects in the } \\
\text { engineering collaboration. } \\
\text { 2. Focused on integrating the cash flow, delivery and engineering } \\
\text { collaboration for the local electronic companies and semi conductor } \\
\text { manufacturers which are based on the companies' projects in their } \\
\text { e-cash flow system. } \\
\text { 3. Enhanced services such as e-cash, e-delivery and e-engineering } \\
\text { collaboration, to help the involved companies integrate the supply } \\
\text { chain and cash flow into the Industry Automation Programme. }\end{array}$ \\
\hline
\end{tabular}


Diversifying into complex products has increased case companies' communication requirements which are already complex. For example, case companies need to work

with more than 500 suppliers and dozens of customers, but must now also cope with an increasing pace of change that has seen product life cycles shorten considerably. It is therefore now essential for case companies to be able to understand the status of their suppliers and the impact of that status on their own manufacturing processes, so that customers can be assured that they will receive products in a timely manner. Efficiency and visibility decide the competitiveness of a supply chain system. Nowadays, companies are competing by supply chain systems instead of by individual companies. The better a supply chin system's integration capability, the more chips it holds to beat the competition with (Chen et al., 2004).

On the other hand, the government also reported the following challenges:

\section{Poor EDI-ERP Integration}

The case companies attempted to address their communications issues through the use of EDI systems for the various suppliers of, for example, motherboard components, etc. This solution did not, however, deliver substantial benefits, as few suppliers had an IT infrastructure of sufficient complexity to operate EDI. Nor did the EDI system selected by case companies interface well with the ERP systems operating their manufacturing systems, or those used by some of their suppliers. This lack of integration hampered the hoped-for transparency that would facilitate the enhanced levels of customer service required. This lack of integration forced case companies to communicate with some suppliers manually, by fax or telephone. Manual communication was even required for those suppliers operating their own ERP systems, a situation deemed unacceptable in a quest to reach the standards required by customers. Thus, case companies and their suppliers and customers are seeking open, standards-based communication. This was how the Industry Automation Programme started. The case companies therefore decided to put in place systems that would allow electronic procurement for as many suppliers as possible, while also providing links to customers and partners. Hence, they decided that their traditional EDI procurement mechanisms must be replaced by a $\mathrm{B} 2 \mathrm{~B}$ e-commerce mechanism, and its replacement must be standards-based, as only by adopting standardised data interchange mechanisms would they be able to meet the future needs of any possible type of supply chain integration. To address these issues, the case companies worked with their suppliers to ensure they adopt the RosettaNet ${ }^{3}$ standards to describe electronic transactions and implement this standard in their ERP systems. Moreover, the technical problems mentioned in this section have caused some supply chain problems, and these are discussed in the next section.

\section{Competition}

For decades, industries in Taiwan have gained benefits from acquiring technology. Through this continuing acquiring and adaptation process, the thrust of industrial development over the past decade has created a closely knit and very competitive industry verticalisation, especially in hi-tech manufacturing and semiconductor industries, which represent very interdependent industry webs, with many buyers and many suppliersand with an increasing international B2B relationship.

\footnotetext{
${ }^{3}$ RosettaNet which has been used in this 'A, B Plan' programme is an XML-based standard built for use in the IT industry. RosettaNet is a 'global business consortium' creating the electronic commerce framework to align processes in the IT supply chain. Founded in 1998, RosettaNet is an independent, self-funded, non-profit consortium dedicated to the development and deployment of standard electronic commerce interfaces to align the processes between IT supply chain partners on a global basis.
} 
While acquiring technology is not a panacea for all, the reality is that for major manufacturers with active market development outside of Taiwan or for those which have very close business relationships with partners overseas, the quality and market acceptance, and play a dominating role in the overall economy in Taiwan, acquired technology, technological products and services will continue to play an important role in supporting the fast growth of key industries in Taiwan.

In the realm of business IS, the acquired technology ranges from high-performance business servers and networking (the 'e-infrastructure') to enterprise solutions such as in ERP, Customer Relationship Management, manufacturing execution system, product development management, supply chain execution, supply chain management, and B2B/B2C eMarketplace applications and models. The rapid growth of the Internet as a medium, through which businesses can communicate, streamline business processes, and transact more efficiently, has elevated the level of global competition. Escalating market dynamics like time-to-market pressures, high customisation demands, and increased dependence on outsourcing have elevated slow process cycles, etc. These situations have improved since the case companies started integrating their supply chain. The suppliers involved in the Industry Automation Programme reported that: "It is hard to please every customer, thus I would only say the adaptation to the integrated IT infrastructure has pleased some of the customers, not all of them appreciate the improved efficiency."

\section{Other external challenges}

The government agents interviewed in this study mentioned additional challenges faced by them in their effort to succeed with the Industry Automation Programme. These are:

- The consistency of the government's economic policy will affect further Industry Automation Programme

- The change in the economic situation, i.e. the economic downturn, will influence the companies' involvement in demand for acquired technology is higher, and sometimes becomes an indispensable part of business infrastructure. While the domestically available technology and services have made an enormous stride in

B2B collaboration to core competency status. Companies must not only find more efficient ways to share information internally, they must also find ways to collaborate with their business partners, suppliers and customers. Therefore, in this new Internet economy, it is not about Company A vs. Company $B$, it is about supply chain $A$ vs. supply chain $B$.

It is for the above reasons that most of the large companies adopt not only Internet-based EDI or B2B integration technologies, but also emerging technologies like EAI or Web Services. However, unlike these large companies, most SME suppliers were not able to move one step forward to follow the large companies to adopt EAl or Web Services due to their characteristic weaknesses, e.g. lack of resources such as finance, time, and expertise. Before the implementation of supply chain integration, the large companies and their suppliers faced several problems like slow purchasing processes,

the project, or the companies will cut their Industry Automation Programme budget and use it for other more urgent matters instead.

- The employee turnover rate will create some difficulties for the companies that adopt the Industry Automation Programme to continue with the project.

- Some companies' Industry Automation Programme will be terminated by the companies when they close their business in the market.

This section reports the details and results of the Industry Automation Programme. In the next section, the findings will be discussed.

\section{Discussion}

Based on the interview data reported in the last section, it was found that in many cases, a company may adopt a technology due to influences exerted by its business partners, its competitors and the government, and it 
has nothing to do with the technology or the organisation itself. Pressures from the government, business partners or competitors have been found to be an important factor in integrating technologies' adoption decisions. Thus, external pressure tends to be an adoption factor for SMEs. Although not many large organisations emphasised external pressure as a factor, some did report that the main pressure they received was from the government, since this project was government-funded. The case companies need to report their progress to the project committee members at certain times. This situation might be expected to be different for those companies not sponsored by the government. According to our findings, SMEs tend to overemphasise the costs issue more than anything else when they consider applying integrations technologies within their companies. Some SMEs suppliers reported that:

"Cost is the major concern, as they do not want to spend too much money on adopting integration technologies if they can develop their own systems that will be compatible to their other systems".

Some micro suppliers also reported that: "Since they do not have many systems within the organisations, adopting integration technologies to support their supply chain would only add complexity and extra costs".

This again proves the importance of the government support in terms of helping SMEs to integrate supply chain and to provide the SMEs a platform to share information across supply chain (Lee and Kim, 2007). Since the basic integration need for SMEs is to increase business efficiency, which is similar to the purpose of integrations technologies adoption within large organisations, the consideration of the cost issue may give them less benefit and create integration related problems and long term negative effects to the organisations' sustainability. To cope with these problems, one possible solution is to enable managers within SMEs to understand the importance of adapting to an integrated IT infrastructure, i.e. to solve its integration problems and to secure its competitiveness. According to our interview data, one manager from SMEs claimed that: "It is hard to judge whether the adoption of integration technologies has actually helped us to achieve a higher return on investment as I cannot give you an actual figure".

SMEs should not ignore the problems or issues that arise from a non-integrated IT infrastructure as it may affect business processes, delay fulfilment of customer orders and impact upon customer satisfaction. Learning from large organisations, it is advisable that SMEs' managers do not utilise 'cost' as the only motivating factor to adapt to an integrated architecture. Instead, for long-term benefits, the following issues should also be considered as the motivating factors to adopt integration technologies: (1) to support manufacturing processes, (2) to retain their competitiveness, (3) to support their future needs for any possible type of supply chain integration, and (4) to fulfil the transparency that would facilitate the enhanced levels of customer service required. The role of the government is due to the cost factor emphasised here, as the financial support received by the government can be a differentiating factor in the SMEs' decision to adopt or not. Moreover, the empirical data show that IT sophistication, adopter characteristics, and support tend to have a medium-to-high impact on SME suppliers' adoption decisions. The researcher found that organisations like SMEs found it particularly hard to adopt integration technologies without any kind of support (e.g. not only support from vendors and consultants, but also from the government and large companies, etc.) due to their characteristic weaknesses, e.g. lack of 'know-how' and resources.

In addition, it was found that when the purchasing amount and frequency are high from the large companies, suppliers are more willing to adopt integration technologies to support their supply chains. Thus, this demonstrates that suppliers are highly dependent on their trading partners for their integration technologies' adoption to support their supply chains. In other words, many SMEs (e.g. suppliers) are part of the supply chain networks, thus, even though 
they are facing problems like lack of resources, they will still go ahead with their adoption decisions with the support from governments or their buyers. These behaviours reflect the firms' external dependencies. Thus, the authors suggest that the supply chain network should be an additional variable to SMEs' integration technologies adoption decisions. The authors also argue that not only the resources constraints but also the resource-dependency theory is important to explain SMEs' integration technologies adoption decisions. For these reasons, the authors suggest that, with the external support/pressure from governments and buyers, for example, SMEs' resources limitations do not always have an impact on their integration technologies adoption decisions. In other words, resource constraints is no longer an issue to SMEs' integration technologies adoption as they have to adopt these technologies as they are part of the supply chain network. The discussion here provides the answer to the Research Issue $\left(\boldsymbol{R I}_{\boldsymbol{1}}\right)$ : SMEs' integration technologies adoption decisions are sometimes highly dependent on whether SMEs are part of the supply chain network or part of a large e-government initiative.

\section{Conclusions and Future Prospects}

In an era of globalisation and integration, a business has to find ways to strengthen its supply chain. Supply chain integration is an important issue for organisations, since it allows them to take competitive advantage and improve their business processes. The IT manufacturers and their suppliers in Taiwan need to improve their business processes in order to gain competitive advantage to avoid being eliminated. On the other hand, those enterprises that seriously build up a new business strategy and re-position themselves have better opportunities to sustain themselves and, at least, to survive.

In this paper, a government initiative towards the integration of the supply chains of Taiwan's SMEs is explored using a case study cycle strategy. The paper has opened several often neglected topics in e-Government (Groznik and Trkman, 2009), specifically the possibilities and challenges of SCM. The empirical data show that SMEs are moving to the adoption of integrated systems as a way to improve efficiency by interconnecting their systems with their suppliers and customers to automate the supply chain process, hence, increasing competitive advantages. Additionally, as the case companies were supported by the Taiwanese government financially and technically to integrate their supply chains, the government in this case played an important role in assisting SMEs to achieve supply chain integration. Taiwan's government has followed a similar approach as Singapore where its government supported the industries to promote e-business application ability to increase competitive advantages, e.g. the Logistics Enhancement Applications Programme in 1997 and the TradeNet Plus programme to develop a complete e-business transaction system in 2001. As mentioned before, SMEs are relatively weak in technological ability and financial resources, therefore government support (i.e. an external driver) can be another important factor motivating the adoption of supply chain integration in SMEs.

Moreover, the case study reported in this paper shows not only that the government promotion mechanisms and increasing pressure on firms can be a major enabler for IT adoption in SMEs, but also whether SMEs are part of the supply chain network or part of a large e-government initiative and culture are important factors. By adopting supply chain integration with the support from the government, the local suppliers and the local manufacturers are not only able to improve their technological abilities and application level of B2B e-commerce, but also the manufacturers' international competence is enhanced and the procurement from important international buyers is also increased. This is due to a faster and more efficient business transaction and communication between the buyers, suppliers and the sellers, according to the analysis made in this paper. By using a common integration/interconnection standard, the suppliers, banks and buyers were able to share the data and services. The empirical evidence also suggests that 
SMEs gain significant advantages when integrating their supply chains.

One of the limitations of this research is that the outcomes presented herein are based on a real life case study. Thus, the data and the observations derived from the case might not be generalised beyond the sample frame. The authors suggest that this could be addressed by cross-sector and cross-cultural studies. For future research, the authors also recommend that the presented methodology should be tested and refined on further cases to ensure its applicability and validity. Nonetheless, it is not the intention of this paper to offer prescriptive guidelines but rather to describe case study perspectives that allow others to relate their experiences to those reported. Hence, this paper offers a broader understanding of the phenomenon of e-government initiatives to support supply chain integration in practice.

\section{References}

Acs, Z. J. and Audretsch, D. B. (1990) Innovation and Small Firms, MIT Press.

Attewell, P. (1992). 'Technology Diffusion and Organisational Learning: the Case of Business Computing', Organisation Science, 3, 1-19.

Audretsch, D. B.(1995). Innovation and Industry Evolution, MIT Press.

Abreu, E. (2001). 'XML is Now the Standard Language for the Internet', IDG.Net, (http://www.thestandard.com/article $/ 0,1902,24180,00 \cdot \mathrm{html})$, [accessed Nov 2001].

Amrani, E.R., Rowe, F. \& Maronna, B. G. (2006) The effects of enterprise resource planning implementation strategy on cross-functionality. Information Systems Journal, 16, 79-104.

Avgerou, C. (2001) The significance of context in information systems and organisational change. Information Systems Journal, 11, 43-63.

Barney, J. (1991). 'Firm Resources and Sustainable Competitive Advantage', Journal of Management, 17(1), 99-120.

Bell, J., Crick, D., and Young, S. (2004). 'Small Firm Internationalization and
Business Strategy', International Small Business Journal, 22(1), 23-56.

Boyatzis, R. (1998). Transforming Qualitative Information: Thematic analysis

and code development, London, UK: Sage Publications.

Braun, V. and Clarke, V. (2006). 'Using Thematic Analysis in Psychology',

Qualitative Research in Psychology, 3(1): 77-101.

Buccolini, F. (2004). Policies on Health Development and Information and Communication Technologies, In proceedings of the International Conference on e-Health in Developing Countries, May 31 June 1, Rome, Italy.

Burns, P. (2001). Entrepreneurship and Small Business, Palgrave, New York.

Caldeira, M.M. \& Ward, J.M. (2002). Understanding the successful adoption and use of IS/IT in SMEs: an explanation from Portuguese manufacturing industries. Information Systems Journal, 12, 121-158.

Carter, S. and Evan, J. D. (2000). Enterprise and Small Business: Principles, Practice and Policy, Pearson Education, Essex, U.K.

Cegarra-Navarro, J., Dewhurst, F., and Briones Penalver, A. (2007). 'Factors Affecting the Use of E-Government in the Telecommunications Industry of Spain', Technovation, 27(10), 595-604.

Charles, C., Bauer, P. and Bauer, M. J. 2001. E-Supply Chain, Berrett-Koehler Publishers, Inc, San Francisco, CA.

Charlesworth, I., Hamilton, J., Holden, M., Holt, E., Jagger, T., Jennings, T. and Jones, T. (2002). 'EAl and Web Services: Cutting the Cost of Enterprise Integration', In Technology Evaluation and Comparison Report, Butler Group Limited, Hull, Yorkshire, UK.

Chen, H. and Themistocleous, M. (2004). 'Understanding Web Services Benefits and Barriers through Classification and Case Studies', In Proceedings of the European 
Mediterranean Conference on Information Systems (EMCIS), July 25-27, Tunis, Tunisia, CD-ROM.

Chen, H., Themistocleous, M. and Chiu, K. H. (2003). 'Inter-Organisational Application Integration: the Case of 15 Taiwan's SMEs', In Proceedings of the ISOneWorld Conference, April 23-25, Las Vegas, Nevada, USA, CD-ROM.

Chen, H., Themistocleous, M. and Chiu, K. H. (2004). 'Approach to Supply Chain Integration Followed by SMEs: an Exploratory Case Study', In Proceedings of the Americas' Conference on Information Systems (AMCIS), Aug 6-8, New York, USA, CD-ROM.

Chopra, S. and Meindl, P. (2001). Supply Chain Management: Strategy, Planning and Operation, Prentice Hall, NJ.

Choudrie J., Papazafeiropoulou A., Lee, $\mathrm{H}$. (2003) 'A Web of Stakeholders and Strategies: A Case of Broadband Diffusion in South Korea', Journal of Information Technology, 18, 4, 281-291.

Ciborra, C., Navarra, D.D. (2005) 'Good Governance, Development Theory, and Aid Policy: Risks and Challenges of E-Government in Jordan', Information Technology for Development, 11, 2, 141-159.

Cragg, P. B. and Zinatelli, N. (1995). 'The Evolution of Information in Small Businesses', Information and Management, 29(1), 1-8.

Currie, W.L. \& Willcocks, L.P. (1998) Analysing four types of IT sourcing decisions in the context of scale, client/supplier interdependency and risk mitigation. Information Systems Journal, 8, 119-143.

Dass, K. (2002). 'Supply Chain Integration Solutions', Sytlusinc, (http://www.stylusinc.net/technolog $\mathrm{y} / \mathrm{microsoft} /$ supplychain.shtml), [accessed Nov 2001].

Darin, P. (2002). 'Using Web Services for Integration', Darin Partners and Zap Think, (http://www.xml.org/xml/wsi.pdf), [accessed March 2003].

Davis, W. (1990). The Innovators in Henry, J. and Walker, D. (eds) Managing
Innovation, Sage Publications.

Denzin, N. Y. K. (1978). The Research Act: A Theoretical Introduction to Sociological Methods, McGraw, New York.

Daniel, E. (2003). 'An Exploration of the Inside-Out Model: E-commerce Integration in UK SMEs', Journal of Small Business and Enterprise Development, 10(3), 233-249.

Deakins, D. and Freel, M. (2003). Entrepreneurship and Small Firms, Third Edition, McGraw-Hill Education, Berkshire, U.K.

Essig, M. and Arnold, U. (2001). 'Electronic procurement in supply chain management: An information economics-based analysis of electronic markets', The Journal of Supply Chain Management, 37, 43-49.

European Commission (2003). 'Enterprise Policy', European Commission, (http://europa.eu.int/comm/index_e n.htm), [accessed Jan 2003].

Fazeela Ahsan, M.J.F and Herath, S.K. (2006). 'Adoption of e-commerce in Small and Medium Enterprises: with special reference to the Sri Lanka-based apparel industry', International Journal of Management and Enterprise Development, 3(6), pp. 579-598.

Farn, C.K., Hwang, M.D., Hwang. Syming, Liu Y. C, (2005), ABCDE Plan and Research Results Collection, Department of Industrial Technology, Ministry of Economics, Taiwan. Gallivan, M.J. \& Keil, M. (2003). The user development communication process: a critical case study. Information Systems Journal, 13, 37-54.

Gibbs, J., Kraemer, K.L., Dedrick, J. 'Environment and policy factors shaping global e-commerce diffusion: a cross-country comparison', The Information Society 19, 5-18.

Gibson, T. (2001). 'The Importance of SMEs to Central Asia and the Importance of Equity for SMEs', Institute for SME

Finance, (http://www.smeinstitute.org/semina rs/asia

/english/importance.pdf), [accessed 
Dec 2002].

Gil-Garcia, J.R., Pardo, T.A. (2005). 'E-government success factors: Mapping practical tools to theoretical foundations', Government Information Quarterly 22, 187-216.

Groznik, A., Kovacic, A., \& Trkman, P. (2008). 'The Role of Business Renovation and Informatization in E-Government', Journal of Computer Information Systems, 49(1), 80-88.

Groznik, A. and Trkman, P. (2009). 'Upstream Supply Chain Management in e-Government: the Case of Slovenia', Government Information Quarterly, 26(3), 459-467.

Guo, R. and Xu, Y. (2006). 'The Adoption of Internet-Based

Business-To-Business

E-Marketplaces among Small and Medium-Sized Enterprises in their International Marketing Practices', in Proceedings of the 14th European Conference on Information Systems Conference, June 2006, Goteborg, CD-ROM.

Hailstone, R. and Perry, R. (2002). IBM and the Strategic Potential of Web Services: Assessing the Customer Experience, An IDC White Paper, IBM, USA.

Hart, P. J. and Saunders, C. S. (1998). 'Emerging Electronic Partnerships: Antecedents and Dimensions of EDI Use from the Supplier's Perspective', Journal of Management Information System, 14(4), 87-111.

Hayes, N. (1997). Theory-led Thematic Analysis: Social identification in small companies, in N. Hayes (ed.) Doing Qualitative Analysis in Psychology, Hove: Psychology Press, pp. 93-114.

Hughes, M., Golden, W. and Powell, P. (2003). 'Inter-Organisational ICT Systems: the Way to Innovative Practice for SMEs', Journal of Small Business and Enterprise Development, 10(3), 277-286.

Hsu, P., Kraemer, K.L., Dunkle, D.(2006). 'Determinants of E-Business Use in U.S. Firms', International Journal of Electronic Commerce, 10, 4, 9-45. lacovou, C., Benbasat, I. and Dexter, A. (1995). 'Electronic Data Interchange and Small Organisations: Adoption and Impact of Technology', MIS Quarterly, 19(4), 465-485.

Irani, Z., Love, P.E.D., Elliman, T. \& Jones, S. (2005). Evaluating e-government: learning from the experiences of two local authorities. Information Systems Journal, 15, 61-82.

Janesick, V. (2000). 'The Choreography of Qualitative Research Design', In Handbook of Qualitative Research, Sage, Thousand Oaks, CA.

Johnson, Jr., B. L. (1998). Resource dependence theory: A political economy model of organizations. International Encyclopedia of Public Policy and Administration. Jay Shafritz, Editor in Chief. New York: Henry Holt Company. 4: pp. 1969-1974.

Kagan, A., Lau, K. and Nusgart, K. R. (1990). 'Information System Usage within Small Business Firms', Entrepreneurship: Theory and Practice, 14(3), 25-37.

Kaye, D. (2003). Loosely Coupled: the Missing Pieces of Web Services, RDS Press, Marin County, California.

Kirby, A. D. (2003). Entrepreneurship, McGraw-Hill Education, Glasgow, U.K.

Kalakota, R. and Robinson, M. (2001). e-Business: Roadmap for Success, Addison-Wesley, Boston, Massachusetts, USA.

Kuan, K. K. Y. and Chau, P. Y. K. (2001). 'A Perception-Based Model for EDI Adoption in Small Businesses Using a

Technology-Organisation-Environm ent Framework', Information and Management, 38(8), 507-521.

Lee, H. L. and Whang, S. (2001). 'E-Business and Supply Chain Integration', Standford Global Supply Chain Management Forum.

Lee, S., Tan, X. and Trimi, S. (2005). 'Current practices of leading E-Government countries', Communications of the ACM, 48(10), 99-104.

Lee, J. and Kim, J. (2007). 'Grounded theory analysis of e-Government Initiatives: 
Exploring Perceptions of Government Authorities', Government Information Quarterly, 2491), 135-147.

Levy, M., Powell, P. and Yetton, P. (2001), 'SMEs: Aligning IS and the Strategic Context', Journal of Information Technology, 16, 133-144.

Lin, B., Vassar, J. and Clark, L. (1993). 'Information Technology Strategies for Small Business', Journal of Applied Business Research, 9(2), 25-29.

Ling, C. Y. (2001). 'Model of Factor Influences on Electronic Commerce Adoption and Diffusion in Small and Medium Sized Enterprises', In Proceedings of the European Conference on Information Systems (ECIS), June 27-29, Bled, Slovenia, PhD Consortium.

Linthicum, D. (1999). Enterprise Application Integration, Addison-Wesley, Massachusetts.

MOEATD (2001). RosettaNet Standard and B2B E-business, Ministry of Economic Affairs, Technology Department Taiwan.

Mustonen-Ollila, E. \& Lyytinen, K. (2003) Why organizations adopt information system process innovations: a longitudinal study using Diffusion of Innovation theory. Information Systems Journal, 13, 275-297.

Morphy, E. (2003). 'New NetLedger App Links Front, Back Offices', CRMDaily.com, (http://www.crmdaily.com/perl/prin ter/21996/), [accessed Dec 2003].

Mack, Natasha. Woodsong, Cynthia, McQueen, M. K., Guest, Greg, and Namey, Emily (2005), Quality Research Method, Family Health International.

Nurmilaakso, J. M., Kettunen, J. and Seilonen, I. (2001). 'XML-based supply chain integration: a case study', Integrated Manufacturing Systems, 586-595.

Oxley, J.E., Yeung, B. 'E-commerce readiness: environmental international competitiveness', Journal of International Business Studies 32 (4) (2001) 705-723.
Pan, S. L., Tan, C. W. and Lim E. T. K. (2006), 'Customer relationship management (CRM) in e-Government: a Relational Perspective', Decision Support Systems, 42(1), 237-250.

Panayiotou, N., Gayialis, S., and Tatsiopoulos, I. (2004). 'An e-procurement system for governmental purchasing', International Journal of Production Economics, 90(1), 79-102.

Patton, M.Q. (1990). Qualitative Evaluation and Research Methods, 2nd edn,

London, UK: Sage.

Pearce, J. A., Chapman, B. L. and David, F. R. (1982). 'Environmental scanning for small and Growing Firms', Journal of Small Business Management, July, 27-34.

Penrose, E. T. (1959). The Theory of the Growth of the Firm. Wiley, New York.

Pollard, C. E. and Hayne, S. C. (1998). 'The Changing Face of Information Systems Issues in Small Firms', International Small Business Journal, 16(3), 70-87.

Premkumar, G. and Potter, M. (1995). 'Adoption of Computer Aided Software Engineering (CASE) Technology: An Innovation Adoption Perspective', Database Advances, 26(2-3), 105-123.

Rizzoni, A. (1991). 'Technological Innovation and Small Firms: a Taxonomy', International Small Business Journal, 9(3), 31-42.

Ray, A. W. and Ray, J. J. (2006). Strategic benefits to SMEs from third party Web Services: An Action Research Analysis. Strategic Information Systems, 15, 273-291.

Rogers, M. E. (1995). Diffusion of Innovations (Fourth eds.), The Free Press, New York, NY.

RIS (2002). 'Key Performance Indicator Management and Review', Resolution Integration Solution, Inc, (http://www.ris-resolution.com/kpi.s html), [accessed March 2003].

RNT (2001). 'RosettaNet in Taiwan', RosettaNet,

(http://www.rosettanettaiwan.org.tw /), [accessed June 2002].

Sanchez, E., Beery, D. and Shehab, J. 
(2002). 'Review: EAI Systems Bring IT Together', CMP, (http://www.networkcomputing.co $\mathrm{m} / 1302 / 1302 \mathrm{f} 5 . \mathrm{html}$ ), [accessed March 2003].

Saunders, C. and Hart, P. (1993). 'Electronic Data Interchange Across Organisational Boundaries: Building a Theory of Motivation and Implementation', In Proceedings of the Administrative Sciences Association of Canada Twenty-First Annual Conference, May 1993, Lake Louise, Alberta, Canada.

Shang, S. and Seddon, P. (2000). 'A Comprehensive Framework for Classifying the Benefits of ERP Systems', In Proceedings of the Americas Conference on Information Systems (AMCIS), August 11-13, Long Beach, California, USA, 1005-1114.

Shapiro, C. and Varian, H.R. (1999). Information Rules: A strategic guide to the network economy, Boston: Harvard Business School Press.

Shin, I. (2006). Adoption of Enterprise Application Software and Firm Performance. Small Business Economics,26, 241-256.

Shore, B. 'Information sharing in global supply chain systems', Journal of Global Information Technology Management 4 (3) (2001).

Soh, C., Neo, B.S., Markus, M.L. IT 2000: a critical appraisal of Singapore's state-wide strategic planning process for information technology, Journal of Strategic Information Systems 2 (4) 351-357.

Stokes, D. and Wilson, N (2006). Small Business Management and Entrepreneurship (5th Edition), Thomson, London, U.K.

Storey, D. J. (1994). Understanding the Small Business Sector, Routledge, London, U.K.

Storey, D. J and Cressy, R. (1995). Small Business Risk: a Firm and Bank Perspective, Working Paper, SME Centre, Warwick Business School.

Tagliavini, M., Faverio, P., Ravarini, A., Pigni, F. and Buonanno, G. (2002). 'Exploring the Use of ERP systems by SMEs', In Proceedings of the 6th World Multi Conference on
Systematics Cybernetics and Informatics, March 24-28, Orlando, Florida, USA, 14-18.

Themistocleous, M. and Irani, Z. (2001). 'Benchmarking the Benefits and Barriers of Application Integration', Benchmarking: An International Journal, 8(4), 317-331.

Thompson, James A. (1967). Organizations in Action, McGraw-Hill, New York, NY.

Thong, J. Y. L. (2001). 'Resource Constraints and Information Systems Implementation in Singaporean Small Businesses', Omega: The International Journal of Management Science, 29(2), 143-156.

Thong, J. Y. L. and Yap, C. S. (1994). 'CEO Characteristics, Organisational Characteristics and Information Technology Adoption in Small Business', Omega, 23, 429-442.

Thatcher, S. M. B., Foster, W. and Zhu, L. (2006) Electronic Commerce Research and Applications, 5, 92-104.

Trkman, P. and Groznik, A. (2006). 'Measurement of Supply Chain Integration Benefits', Interdisciplinary Journal of Information, Knowledge, and Management, 1.

Trkman, P. and Groznik. A. (2007), 'Introduction of Supply Chain Management Concepts in Government Research and Practice', In Proceeding of 6th WSEAS International Conference on e-Activities, DEC 14-16, Puerto de la Cruz, SPAIN.

Wade, M. and Hulland, J. (2004). 'The Resource-Based View and Information Systems Research: Review, Extension, and Suggestions for Future Research', MIS Quarterly, 28(1), 107-142.

Wang, E.H., (1999) 'ICT and economic development in Taiwan: analysis of the evidence', Telecommunications Policy 23 235-243.

Welsh, J. A. and White, J. F. (1981). 'A Small Business is not a Little Big Business', Harvard Business Review, 59(4), 18-32.

Wernerfelt, B. (1984). 'A Resource-Based 
View of the Firm'. Strategic Management Journal, 5, pp. 171-180.

W3C (2002). 'Extensible Markup Language (XML)',W3C,

http://www.w3.org/XML/), [accessed March 2003].

Yildiz, M., (2007) E-government research: Reviewing the literature, limitations, and ways forward, Government Information Quarterly, 24, 646-665.

Yin, R. K. (1994). Case Study Research, Design and Methods, Sage, Newbury Park, CA.

Yuan, E. (2000). Electronic Business White Paper Taiwan: In the Age of Electronic Business and the Digital Economy, Compiled and Printed by iAeB Program Office, Taipei, Taiwan.

Yuan, E. (2000). Electronic Business White Paper Taiwan: In the Age of Electronic Business and the Digital Economy, Compiled and Printed by iAeB Program Office, Taipei, Taiwan.

Yuan, E. (2000). Electronic Business White Paper Taiwan: In the Age of Electronic Business and the Digital Economy, Compiled and Printed by iAeB Program Office, Taipei, Taiwan.

Zahavi, R. (1999). Enterprise Application Integration with CORBA, Wiley, New York, USA.

Dr. Hsin Chen is a lecturer in the Business Systems Department at Bedfordshire University, UK. She has been involved in a number of UK funded research projects with emphasis on entrepreneurship and Small and Medium Size Enterprises (SMEs). Her research interests include the adoption and impact of integration technologies, small business management, Enterprise Recourse Planning Systems (ERPs), entrepreneurship, and e-commerce.

Dr Anastasia Papazafeiropoulou is a senior lecturer in the Information Systems and Computing department at Brunel University, UK. Her research experience involves the study of diffusion and adoption of electronic commerce, broadband Internet, Enterprise
Recourse Planning Systems (ERPs), Customer Relationship Management systems (CRMs), IP-telephony and mobile TV.

Chingfang $\mathrm{Wu}$ is a lecturer in the Business Administration department at $\mathrm{Yu}$ DA University, Taiwan. She holds a Master degree in Human Resources from Warwick University and she also has researched in the topics of human resources management and IT adoption. 